\title{
The influence of High Energy Electron Irradiation on the Schottky Barrier height and the Richardson constant of Ni/4H-SiC Schottky Diodes
}

\author{
E. Omotoso ${ }^{1,2, a)}$, W.E. Meyer ${ }^{1}$, F.D. Auret ${ }^{1}$, A.T. Paradzah $^{1}$, M. Diale ${ }^{1}$, S.M.M. Coelho ${ }^{1}$ \\ and P.J. Janse van Rensburg ${ }^{1}$ \\ ${ }^{1}$ Department of Physics, University of Pretoria, Private Bag X20, Hatfield 0028, South Africa \\ ${ }^{2}$ Departments of Physics, Obafemi Awolowo University, Ile-Ife, 220005, Nigeria \\ a) Corresponding author's e-mail address and contact number: ezekiel.omotoso@up.ac.za; +274842911287
}

\begin{abstract}
The influence of high energy electron (HEE) irradiation from a $\mathrm{Sr}-90$ radio-nuclide on $\mathrm{n}$-type $\mathrm{Ni} / 4 \mathrm{H}-\mathrm{SiC}$ samples of doping density $7.1 \times 10^{15} \mathrm{~cm}^{-3}$ has been investigated over the temperature range 40-300 K. Currentvoltage $(I-V)$, capacitance-voltage $(C-V)$ and deep level transient spectroscopy (DLTS) were used to characterize the devices before and after irradiation at a fluence of $6 \times 10^{14}$ electrons-cm ${ }^{-2}$. For both devices, the $I-V$ characteristics were well described by thermionic emission (TE) in the temperature range 120 - $300 \mathrm{~K}$, but deviated from TE theory at temperature below $120 \mathrm{~K}$. The current flowing through the interface at a bias of 2.0 $\mathrm{V}$ from pure thermionic emission to thermionic field emission within the depletion region with the free carrier concentrations of the devices decreased from $7.8 \times 10^{15}$ to $6.8 \times 10^{15} \mathrm{~cm}^{-3}$ after HEE irradiation. The modified Richardson constants were determined from the Gaussian distribution of the barrier height across the contact and found to be 133 and $163 \mathrm{Acm}^{-2} \mathrm{~K}^{-2}$ for as-deposited and irradiated diodes, respectively. Three new defects with energies $0.22,0.40$ and $0.71 \mathrm{eV}$ appeared after HEE irradiation. Richardson constants were significantly less than the theoretical value which was ascribed to a small active device area.
\end{abstract}

Keywords: Richardson constant, high energy electron irradiation, silicon carbide, Schottky barrier height

\section{Introduction}

Metal-semiconductor (MS) Schottky barrier diodes (SBDs) are widely used where diodes with low forward voltage drop, junction capacitance and high switching speed are required [1]. This makes them ideal as rectifiers in photovoltaic systems, high-efficiency power supplies and high frequency oscillators [2]. SBDs also have important uses in optoelectronics, high frequency and bipolar integrated circuits applications [3, 4]. The reliability of SBDs is influenced significantly by the quality of the MS junction [5]. The performance of the devices can be quantified experimentally study in terms of their ideality factor, Schottky barrier height (SBH), saturation current, series resistance and free carrier concentration. Among these properties of the MS interface, SBH plays a major role in the successful operation of many devices in transporting electrons across the MS junction [6].

Since room temperature $(300 \mathrm{~K})$ measurements of $I-V$ and $C-V$ characteristics alone cannot provide detailed information about the mechanisms responsible for the formation of barrier at the interface of the MS and electrical properties of devices [7], additional insight is gained by characterising the diodes over a wide temperature range $(40-300 \mathrm{~K})$. Conclusions may be drawn from the deviation of $I-V-T$ characteristics from the ideal thermionic emission current model at lower temperature for many SBDs. The $I-V$ - $T$ characteristics of SBDs based on TE theory reveals an abnormal increase in the ideality factor and a decrease in the SBH with 
decreasing temperature [8-11]. The abnormal behaviour has been attributed to be a function of the atomic structure, and atomic or barrier inhomogeneities at the MS interface, which are caused by defects, multiple phases and grain boundaries. The barrier inhomogeneities in MS SBDs are often modelled as a Gaussian distribution function and used to provide better understanding to experimental $I$ - $V$ characteristics [12-15].

$\mathrm{SiC}$ is a promising semiconductor with a wide bandgap of $3.26 \mathrm{eV}$ [16]. Because of its wide bandgap and chemical stability, it can be used to produce electronic devices that are capable of operating at high temperature, high frequency and high power semiconductor devices, as well as in harsh radiation fields [17-20]. Effects of radiation and temperature on semiconductors are technologically important for radiation to sensing applications, as well as manufacturing processes and high temperature and high power applications [21]. Deep level transient spectroscopy (DLTS) on SBDs is often used to investigate the properties of radiation induced defects in semiconductors.

Many researchers have reported that some wide bandgap semiconductors such as $\mathrm{SiC}, \mathrm{ZnO}$ and $\mathrm{GaN}$ are radiation hard which makes them suitable for use in harsh radiation environments [18]. Effects of proton, fast electron and fast neutron irradiation on $\mathrm{SiC}$ have been investigated by different researchers [18, 22-24]. To the best of our knowledge, the effect of high energy electron (HEE) irradiations at fluence of $6 \times 10^{14} \mathrm{~cm}^{-2}$ on $\mathrm{Ni} / 4 \mathrm{H}-\mathrm{SiC}$ has not been reported.

In this work, we present the effect of HEE irradiations on the electrical characteristics of nickel SBDs fabricated on $4 \mathrm{H}-\mathrm{SiC}$ SBDs measured over wide temperature range $(40-300 \mathrm{~K})$. The major aim of this work is to determine the extent to which the characteristics of nickel on n-type $4 \mathrm{H}-\mathrm{SiC}$ Schottky diodes would be affected by HEE irradiations.

\section{Experimental Procedure}

The samples used for this work were cut from a nitrogen-doped $n$-type $4 \mathrm{H}-\mathrm{SiC}$ wafer, polished on both sides with the Si face epi ready, resistivity of $0.02 \Omega-\mathrm{cm}$ and doping density of $7.1 \times 10^{15} \mathrm{~cm}^{-3}$. The wafers were supplied by CREE Res. Inc. The samples were cut into smaller pieces with dimension of roughly $2 \times 3 \mathrm{~mm}^{2}$ and degreased by boiling for 5 minutes each in trichloroethylene, acetone, methanol and followed by 1 minute rinse in de-ionized water. They were etched in $40 \%$ hydrogen fluoride for 30 seconds in order to remove the native oxide layer on the samples, then rinsed in de-ionized water, followed by blow drying with nitrogen gas prior to thermally fabrication of nickel ohmic contact on the back surface $\left(1.0 \times 10^{18} \mathrm{~cm}^{-3}\right.$ doped side $)$ of the samples.

Resistive evaporation was employed for the fabrication of nickel ohmic and Schottky contacts because it is known to neither introduce defects nor contaminate the samples. The ohmic contact with a thickness of 3000 $\AA$ was deposited at a rate of $0.4 \AA \mathrm{s}^{-1}$. For ohmic contact formation, the samples were annealed in a tube furnace under flowing argon gas at $950{ }^{\circ} \mathrm{C}$ for 10 minutes to form nickel silicides [25].

Before deposition of the Schottky contact, the samples were cleaned in an ultrasonic water bath for 3 minutes each in trichloroethylene, acetone and methanol, followed by 1 minute rinsed in de-ionized $\mathrm{H}_{2} \mathrm{O}$ after the annealing of the ohmic contact. Nickel Schottky contacts were resistively evaporated through a metal contact mask and had an area of $2.4 \times 10^{-3} \mathrm{~cm}^{2}$ and a thickness of $1000 \AA$ deposited at a rate of $0.2 \AA \mathrm{s}^{-1}$ under a vacuum of approximately $10^{-5}$ Torr.

The sample was irradiated through the Schottky contacts by HEE from a strontium-90 radioactive source at a fluence rate of $7 \times 10^{9}$ electrons- $\mathrm{cm}^{-2} \mathrm{~s}^{-1}$. The irradiation was carried out at room temperature and lasted for 
24 hours, which resulted in a fluence of $6 \times 10^{14}$ electrons- $\mathrm{cm}^{-2}$. The energy distribution of electron emitted by strontium-90 radionuclide has been reported by Auret et al [26].The sample was characterized at room temperature and in the dark using $I-V$ and $C$ - $V$ station, consisting of a HP $4140 \mathrm{~B}$ pA meter/DC voltage source and HP 4192A LF Impedance Analyzer, respectively. Hereafter, the sample was placed in a closed cycle helium cryostat and characterised by conventional DLTS, $I-V-T$ and $C-V-T$ measurements in wide temperature range. This procedure was performed before and after HEE irradiation.

\section{Results and Discussion}

\subsection{C-V Characteristics}

The fabricated devices were subjected to irradiation at room temperature. Both as-deposited and irradiated devices were examined by the $C-V$ method at different temperatures. Fig. 1 shows the plot of



Fig. 1. The $\mathrm{C}-\mathrm{V}$ characteristics of Schottky barrier diodes of $\mathrm{Ni} / \mathrm{n}-4 \mathrm{H}-\mathrm{SiC}$ before and electron irradiation in temperature range $40-300$ K.

capacitance as a function of reverse bias voltage. The capacitance decreased with a decrease in temperature. The capacitance increased with decreasing reverse voltage for both, but the capacitance after irradiation was lower, as also be reported $[27,28]$. The $C^{-2}\left(\mathrm{pF}^{-2}\right)$ as a function of reverse bias voltage, $V(\mathrm{~V})$ before and after HEE irradiation measured at $1 \mathrm{MHz}$ with the samples at temperatures range 40-300 K are depicted in Fig. 2. The result obtained showed a good SBDs for both devices. There was no abrupt degradation between the asdeposited and irradiated devices at temperature range 80-300 K. The $C$ - $V$ characteristics changed more rapidly with temperature, and the difference between the as-deposited and the irradiated diodes became more 


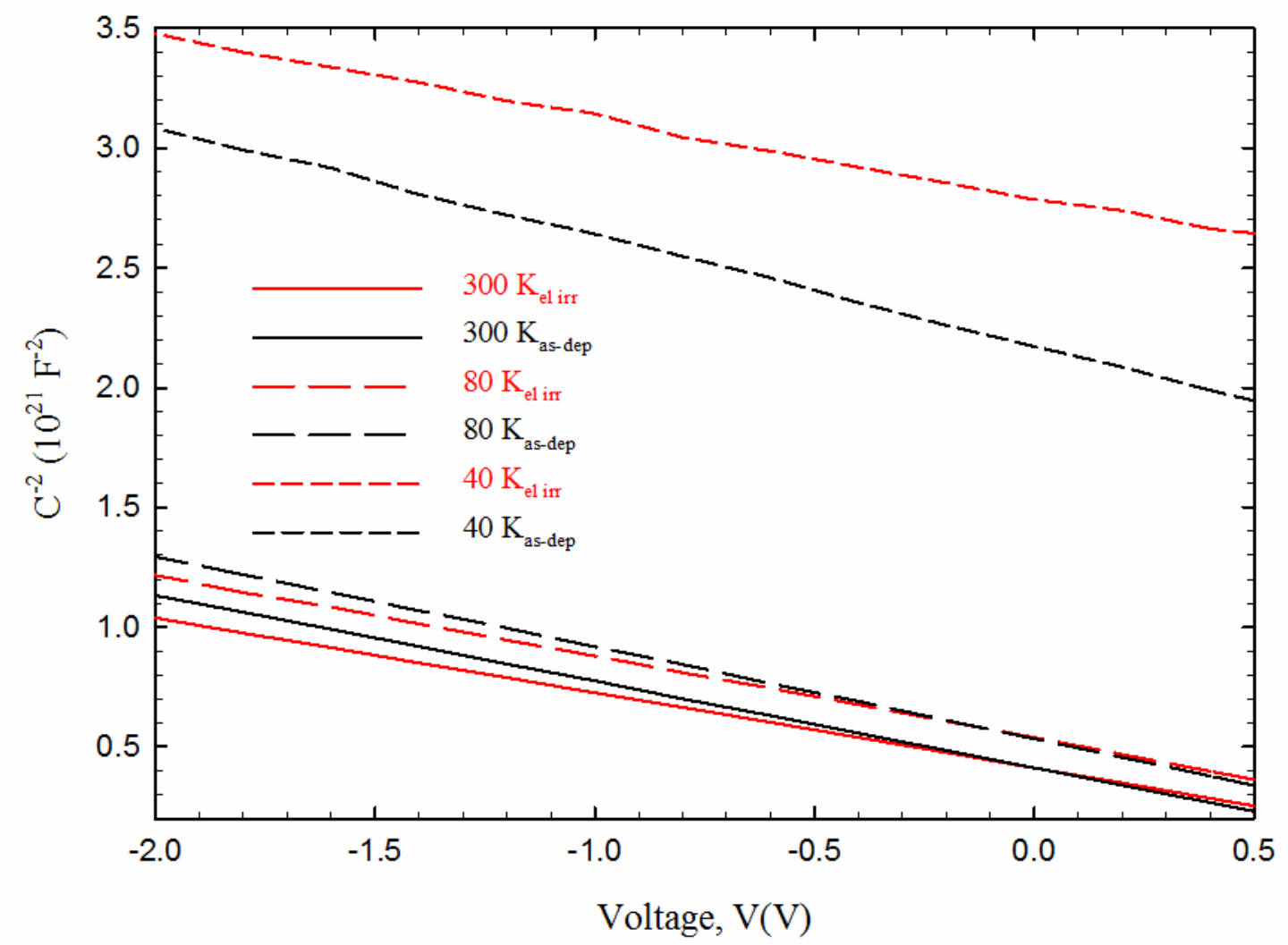

Fig. 2. Graph of $\mathrm{C}^{-2}$ as a function of applied voltage characteristic of SBDs of $\mathrm{Ni} / 4 \mathrm{H}-\mathrm{SiC}$ before and after electron irradiation in temperature range $40-300 \mathrm{~K}$.

pronounced below $80 \mathrm{~K}$. The slope of plot $C^{-2}$ versus $V$ is approximately constant for the temperature range 80$300 \mathrm{~K}$ for both samples which indicates that all the dopant is ionized due to the presence of the electric field [29]. The plot in Fig. 2 is deduced from Eq. 1 which represents the depletion layer in Schottky diodes. The $N_{t}$, $V_{b i}$ and $\phi_{C-V}$, were determined from the plot and tabulated in Table 1 . The free carrier concentrations, $N_{t}$

Table 1. Comparison of some electrical parameters of $\mathrm{Ni} / \mathrm{n}$-type $4 \mathrm{H}-\mathrm{SiC}$ before and after electron irradiation estimated from $I-V$ and $C$ - $V$ characteristics at 40 and $300 \mathrm{~K}$

\begin{tabular}{lccccccc}
\hline Samples & $n$ & $I_{s}(\mathrm{~A})$ & $R_{s}(\Omega)$ & $V_{b i}(\mathrm{~V})$ & $N_{t}\left(\mathrm{~cm}^{-3}\right)$ & $\phi_{I-V}(\mathrm{eV})$ & $\phi_{C-V}(\mathrm{eV})$ \\
\hline As-deposited(300K) & 1.04 & $1.5 \times 10^{-20}$ & 48 & 1.07 & $7.8 \times 10^{15}$ & 1.44 \\
As-deposited (40 K) & 4.02 & $2.0 \times 10^{-44}$ & 664 & 5.03 & $5.9 \times 10^{15}$ & 0.37 & 5.06 \\
24hrs electron Irradiation (300K) & 1.13 & $1.4 \times 10^{-19}$ & 60 & 1.32 & $6.8 \times 10^{15}$ & 1.38 \\
24hrs electron Irradiation (40 K) & 4.14 & $1.4 \times 10^{-45}$ & 1684 & 7.92 & $5.2 \times 10^{15}$ & 0.36 \\
\hline \hline
\end{tabular}

decreased with irradiation and temperature which is as a result of the defects introduced from the HEE irradiation into the $\mathrm{SiC}$.

$$
\frac{1}{C^{2}}=\frac{2\left(V_{o}-V_{b i}\right)}{q \varepsilon_{S} A^{2} N_{t}}
$$

where $q$ is the charge, $\varepsilon_{s}$ is the permittivity of semiconductor, $A$ is the effective area of the diode, and $V_{o}$ can be obtained from the intercept of reverse voltage when $C^{-2}$ is equal to zero. The zero-bias barrier heights for both devices were determined from Eq. 2. 


$$
\phi_{C-V}=V_{b i}+\frac{k T}{q} \ln \frac{N_{c}}{N_{t}}
$$

From Fig. 2, the free carrier concentrations of the sample were determined from the slope of the plots according to Eq. 1. The free carrier removal rate, $y$ can be obtained from Eq. 3 below:

$$
\mathrm{\eta}=\frac{\Delta\left(N_{D}-N_{A}\right)}{\varphi}
$$

where $\Delta\left(N_{D}-N_{A}\right)$ is the change in free carrier concentration before and after HEE irradiation, $\varphi$ is the fluence at which the sample was bombarded [30]. At room temperature (300 K), the change in free carrier concentration from $7.8 \times 10^{15}$ (before irradiation) to $6.8 \times 10^{15} \mathrm{~cm}^{-3}$ (after HEE irradiation) is $1.0 \times 10^{15} \mathrm{~cm}^{-3}$ and the fluence received by the sample was $6.0 \times 10^{14} \mathrm{~cm}^{-2}$. The free carrier removal rate was calculated as $1.67 \mathrm{~cm}^{-1}$ for irradiation of the sample with energy $546 \mathrm{keV}$ from Sr-90 radionuclide. The value of $\mathrm{y}$ calculated here is approximately 4670 times lower than that of $\mathrm{SiC}$ bombarded by $5.4 \mathrm{MeV}$ alpha-particles [31]. The HEE irradiation has less impact on the electrical properties of Ni/4H-SiC than alpha-particle irradiation [31].

\subsection{I-V Characteristics}

The forward semi-log $I-V$ characteristics of the Ni/4H-SiC SBD measured at temperature range 40-300 K before and after electron irradiation are shown in Fig. 3 in order to know the temperature effects on the deep

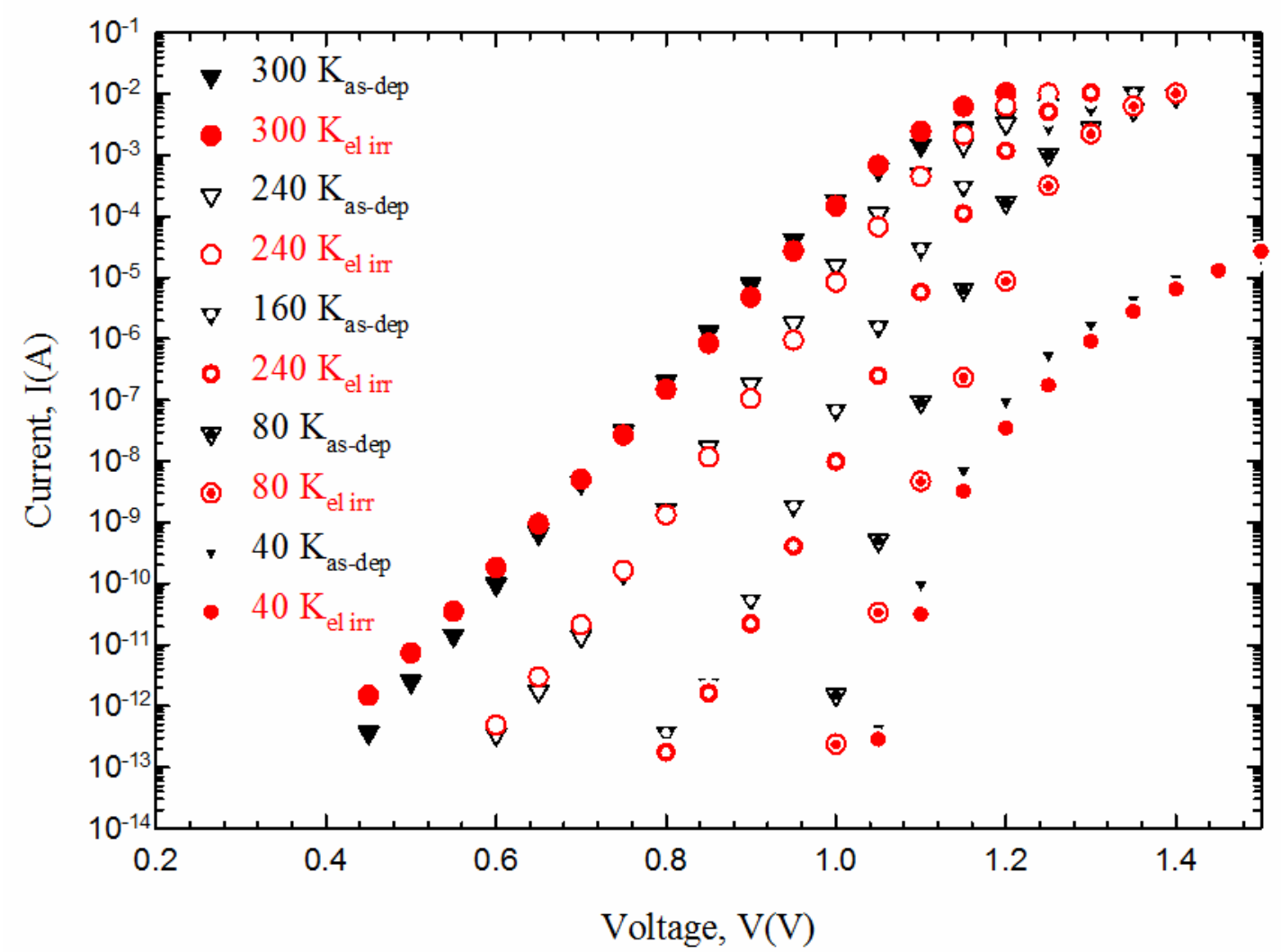

Fig. 3. The current versus voltage characteristics of $\mathrm{Ni} / 4 \mathrm{H}-\mathrm{SiC}$ before and after irradiation measured in temperature range $40-300 \mathrm{~K}$.

energy levels. The plots show linearity up to a current of approximately $1 \times 10^{-4} \mathrm{~A}$ for as-deposited and irradiated devices except at lower temperatures $(80 \mathrm{~K}$ below). It can be observed that $I-V$ plots show lower 
current with lower temperature. This is in accord with the equation describing current transport across a SBD by thermionic emission-diffusion theory $[32,33]$.

The effect of irradiation on the $\mathrm{Ni} / 4 \mathrm{H}-\mathrm{SiC}$ diode as well as temperature can be quantified in terms of the ideality factor $(n)$, Schottky barrier height $\left(\phi_{I-V}\right)$, saturation current $\left(I_{s}\right)$ and series resistance $\left(R_{s}\right)$ obtained from the $I-V$ plots. Measurements on the Schottky contacts were taken before and after the devices were irradiated. Table 1 compares the properties of the samples. The effective Richardson constant for both samples were obtained from the Eq. 4. Schottky barrier heights of the contacts were determined from the $I$ - $V$ characteristics analysed by using the thermionic emission model $[5,32,33]$.

$$
I_{s}=A A^{*} \exp \left(-\frac{q \phi_{I-V}}{k T}\right)
$$

where $A^{*}$ is the effective Richardson constant, $\phi_{I-V}$ is the effective SBH at zero bias, $k$ is the Boltzmann constant and $T$ is absolute temperature in Kelvin.

It could be deduced from Table 1 that the $\mathrm{SBH}_{I-V}$ decrease and the ideality factor increase, with decreasing in temperature [33-37]. It was also observed that $\mathrm{SBHs}_{I-V}$ decrease and the ideality factors increase after HEE irradiation which corroborated what has earlier reported [23, 24], but was in contrast with what was observed by Lin et al [38].

From Eq. 4, $\phi_{I-V}$ is given as:

$$
\phi_{I-V}=\frac{k T}{q} \ln \left(\frac{A A^{*} T^{2}}{I_{s}}\right)
$$

Comparing the $\mathrm{SBH}$ for $I-V$ and $C-V$ measurements, it was observed experimentally that SBHs' do not agree. The SBH increased after irradiation for both $I-V$ and $C-V$, but to greater extent for $C$ - $V$ measurements. This is in agreement with what has been reported in literature [39-43]. The causes for a difference in this parameters are deep impurity levels, surface inhomogeneity, quantum mechanical tunnelling, interfacial layer and states, image force lowering, and edge leakage currents [44].

Fig. 4 shows a gradual change in ideality factor and SBH before and after HEE irradiation for SBD from temperatures above $120 \mathrm{~K}$. It can also be deduced from the plot that there was sporadic deviation of electrical behaviours of SBD from thermionic emission theory at lower temperatures (below $120 \mathrm{~K}$ ). Generationrecombination was dominant at temperatures below $80 \mathrm{~K}$. Ideality factor and $\mathrm{SBH}$ of the Ni/4H-SiC had strong reciprocal temperature dependence at lower temperatures. It was also observed earlier for alpha-particle irradiated devices [31]. These deviations are due to the presence of inhomogeneities at the interface (such as surface defects and inhomogeneity in doping concentration) [20, 33-37, 45-47]. There was little noticeable change in the ideality factors and SBH at temperature $120 \mathrm{~K}$ and above, for before and after irradiation. 


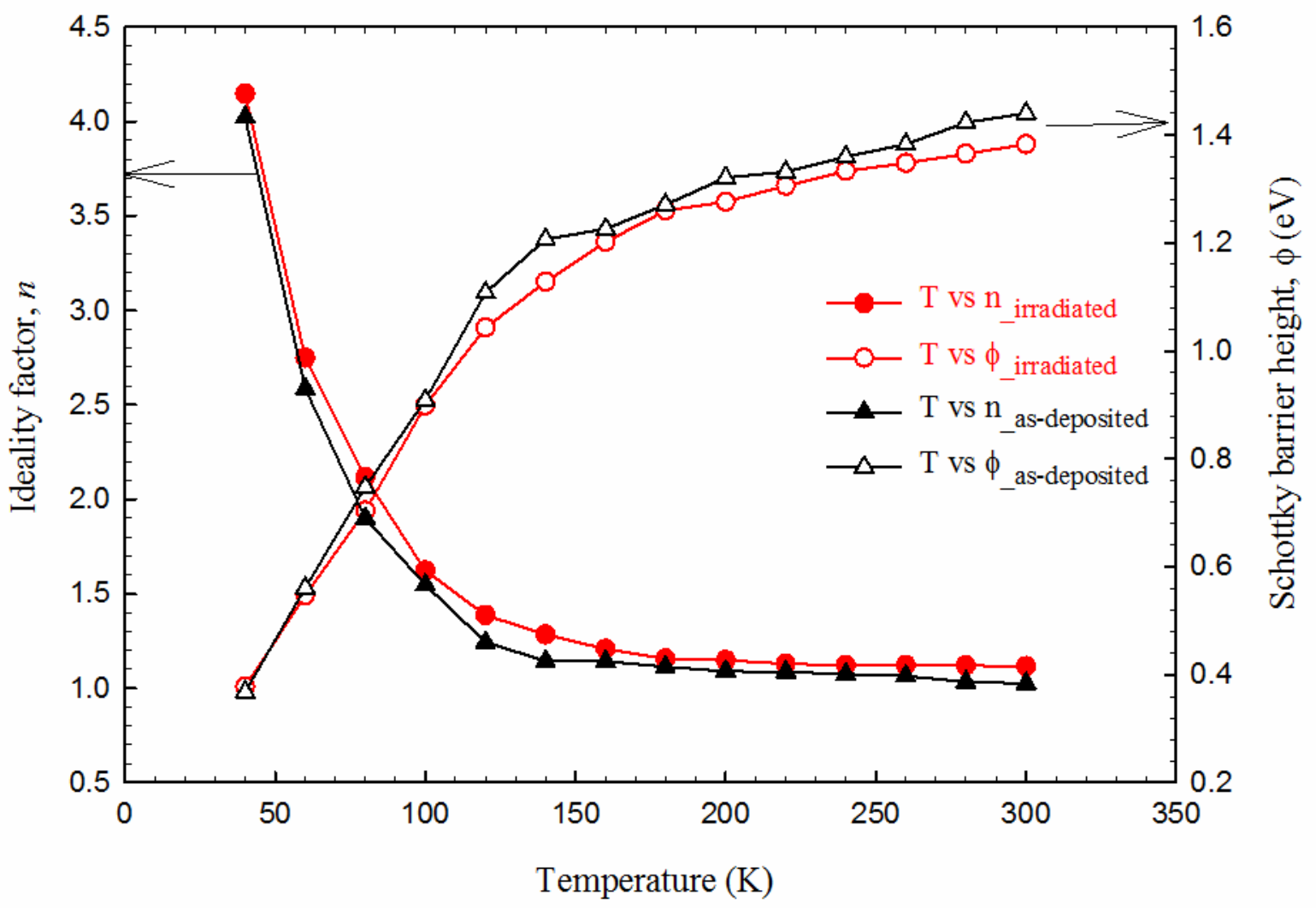

Fig. 4. Ideality factors and Schottky barrier heights as function of temperature before and after irradiation, measured in temperature range $40-300 \mathrm{~K}$.

\subsection{The Richardson plot}

Fig. 5 shows the Richardson's plot of $\ln \left(\mathrm{I}_{\mathrm{S}} / \mathrm{T}^{2}\right)$ as a function of 1/T for as-deposited and HEE irradiated samples. The temperature dependent behaviour of $n$ and SBH predicted an inhomogeneous barrier height and deviation from thermionic emission and diffusion theory as shown in Fig. 4 [20, 34, 37, 47]. Barrier height can be determined in another way by re-writing Eq. 6 as Eq. 9 below;

$$
\ln \left(I_{S} / T^{2}\right)=\ln A A^{*}-q / k \phi_{I-V} \cdot 1 / T
$$

The diode showed very high dependence of ideality factor on temperature, which led to the distortion of the plot from linearity. The plots were linearized by multiplying $\ln \left(I_{s} / T^{2}\right)$ by $n$ as suggested by Schroder [48]. 


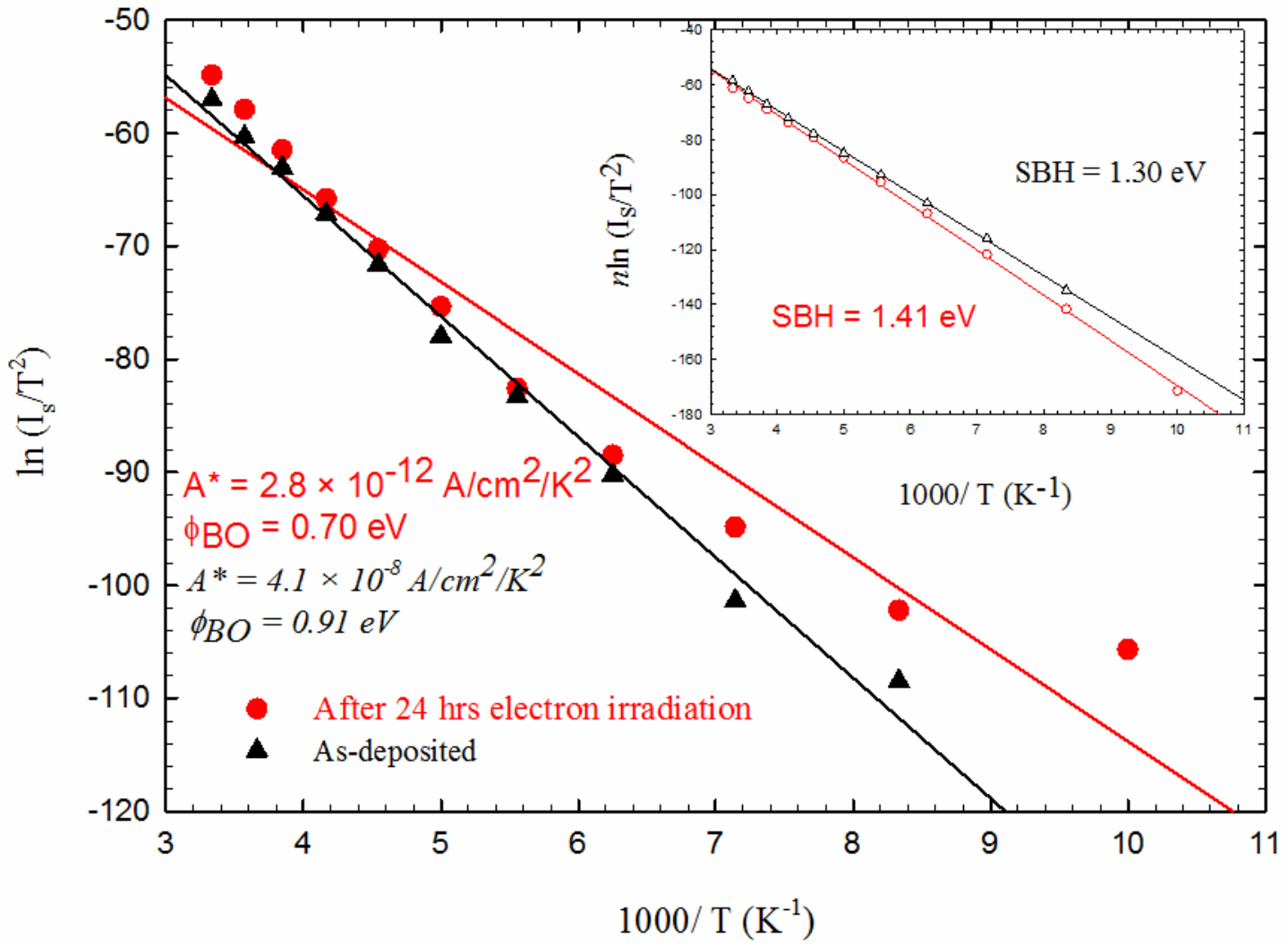

Fig. 5. The Richardson plot, $\ln \left(I_{s} / T^{2}\right)$ versus $1000 / T$ for $\mathrm{Ni} / 4 \mathrm{H}-\mathrm{SiC}$ before and after irradiation in the temperature range $40-300 \mathrm{~K}$. The insert shows the plot of $n\left[\ln \left(I / T^{2}\right)\right]$ versus $1000 / T$.

The experimental values of $A^{*}$ before and after irradiation were estimated from the intercept of the plot to be 4.1 $\times 10^{-8}$ and $2.8 \times 10^{-12} \mathrm{Acm}^{-2} \mathrm{~K}^{-2}$, respectively. The values were extremely small compared to the theoretical value of effective Richardson constant of $146 \mathrm{Acm}^{-2} \mathrm{~K}^{-2}[34,36,37,49,50]$, which indicate that the active area was smaller than the device area [47], and the effect of barrier inhomogeneity [8]. The mean barrier heights for both were deduced from the slope of the insert plot in Fig. 5 to be 1.41 and $1.30 \mathrm{eV}$. It has been reported earlier by many researchers that the deviation of the Richardson constants from theoretical value may be as a result of the effect of the barrier inhomogeneity at the MS interface and some other factors such as crystal defects and potential fluctuation $[8,31,34,47]$. Since the deviation cannot be explained by the thermionic emission diffusion model, the Gaussian distribution model of barrier height has been used.

\subsection{The modified Richardson plot}

The Gaussian distribution model has been used to correct the deviation that cannot be explained with thermionic emission diffusion (TED) which occurred as a result of barrier height inhomogeneities. The abnormal deviation from TE theory has been suggested by some researchers [12, 20, 33-37, 46, 47, 51] that the distribution barrier heights is a Gaussian distribution $P\left(\phi_{B}\right)$ with mean value of SBH $\left(\bar{\phi}_{\mathrm{B}}\right)$ and standard deviation as shown in Eq. 7 [10, 13, 32, 52-54].

$$
P\left(\phi_{B}\right)=\frac{1}{\sigma_{s} \sqrt{2 \pi}} \exp \left(-\frac{\left(\phi_{B}-\bar{\phi}_{B}\right)^{2}}{2 \sigma_{s}^{2}}\right)
$$


where $1 / \sigma_{s} \sqrt{2 \pi}$ is the normalisation constant of the Gaussian barrier height distribution. The total current, $I(\mathrm{~V})$ across the MS of the SBD containing barrier inhomogeneities that can be expressed in integral form in Eq. 8 $[12,13,55]$.

$$
I(V)=\int_{-\infty}^{\infty} I\left(\phi_{B}, V\right) P\left(\phi_{B}\right) d \phi_{B}
$$

where $P\left(\phi_{B}\right)$ is the normalized distribution function that gives probability of accuracy of barrier height, and $I\left(\phi_{B}, V\right)$ is the current, at a bias for barrier height based on the ideal TED theory. The expressions for GD of apparent barrier height, $\phi_{a p}$ at zero bias[10, 11, 56-59] and apparent ideality factor, $n_{a p}$ [57] are derived from Eq. 4 to be Eqs. 9 and 10 as shown below;

$$
\begin{gathered}
\phi_{a p}=\bar{\phi}_{B O}(T=0)-\frac{q \sigma^{2}{ }_{s o}}{k T} \\
\frac{1}{n_{a p}}-1=\rho_{2}-\frac{q \rho_{3}}{2 k T}
\end{gathered}
$$

where $\bar{\phi}_{B}(T=0)$ is the mean barrier height at zero bias and was determined from the intercept of Fig. 6 to be 1.64 and $1.63 \mathrm{eV}$ for as-deposited and after HEE irradiation, respectively, and $\sigma_{s o}$ are standard deviation at zero bias (were determined from the slope of Fig. 6 to be $0.113 \mathrm{eV}$ and $0.104 \mathrm{eV}$ ) and $\rho_{2}$ and $\rho_{3}$ are the voltage

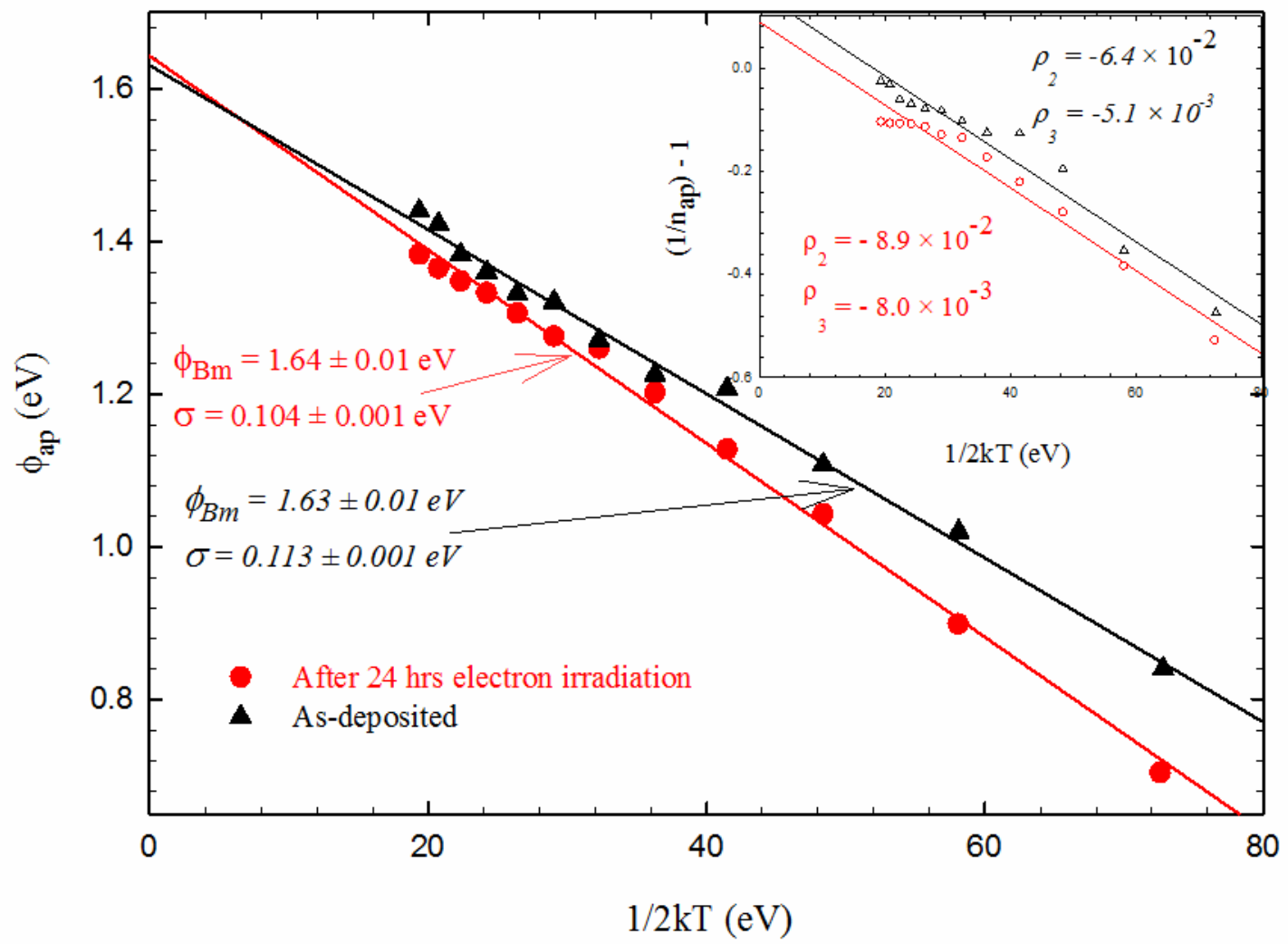

Fig. 6. The zero bias apparent barrier height versus $1 / 2 \mathrm{kT}$ for $\mathrm{Ni} / 4 \mathrm{H}-\mathrm{SiC}$ before and after irradiation. The insert shows the plot of $\left(1 / n_{a p}\right)-1$ versus $1 / 2 \mathrm{k} T$.

coefficients which may be temperature dependent $[34,36]$ and they were obtained from the intercept of the insert of Fig. 6 to be $-8.9 \times 10^{-2}$ and $-8.0 \times 10^{-3}$ (for as-deposited), and $-6.4 \times 10^{-2}$ and $-5.1 \times 10^{-3}$ (after HEE irradiation). The results are tabulated in Table 2. It can be assumed from the results obtained that the $\bar{\phi}_{\mathrm{B}}$ and $\sigma_{s}$ are linearly bias dependent on the parameters of Gaussian $\left(\bar{\phi}_{B}=\bar{\phi}_{B O}+\rho_{2} V\right.$ and $\left.\sigma_{s}=\sigma_{s O}+\rho_{3} V\right)$ and quantifying the voltage deformation of Schottky barrier height distribution [10, 11, 54]. It was observed that the 


\begin{tabular}{lccccccc}
\multicolumn{1}{l}{ Table 2. The characteristics of SBDs of 4H-SiC before and HEE irradiation } & & \\
\hline \hline Samples & $\rho_{2}$ & $\rho_{3}$ & $\sigma_{\mathrm{so}}(\mathrm{eV})$ & $\bar{\phi}_{\boldsymbol{B} \boldsymbol{O}}(T=0)$ & $\bar{\phi}_{\boldsymbol{B}}(\mathrm{eV})$ & $A^{*}\left(\mathrm{Acm}^{-2} \mathrm{~K}^{-2}\right)$ \\
& $\left(\times 10^{-2}\right)$ & $\left(\times 10^{-3}\right)$ & \pm 0.001 & $(\mathrm{eV}) \pm 0.01$ & \pm 0.01 & $A^{* * *}\left(\mathrm{Acm}{ }^{-2} \mathrm{~K}^{-2}\right)$ \\
& -6.4 & -5.1 & 0.113 & 1.63 & 1.64 & $4.1 \times 10^{-8}$ \\
\hline As-deposited & -8.9 & -8.0 & 0.104 & 1.64 & 1.65 & $2.8 \times 10^{-12}$ \\
After electron irradiation & & & & & 133 \\
\hline \hline
\end{tabular}

existence of a Gaussian distribution caused a decrease in zero bias barrier height. The extent of deviation was determined by the standard deviation which is generally significant at low temperature.

The deviation between experimental and theoretical values of the Richardson constants was described by a modified Richardson plot. The modified Richardson constant was obtained by combining Eq. 5 with Eq. 6.

$$
\ln \left(\frac{I_{s}}{T^{2}}\right)-\left(\frac{q^{2} \sigma^{2}}{2 k^{2} T^{2}}\right)=\ln \left(A A^{* *}\right)-\frac{q \Phi_{B m}}{k T}
$$

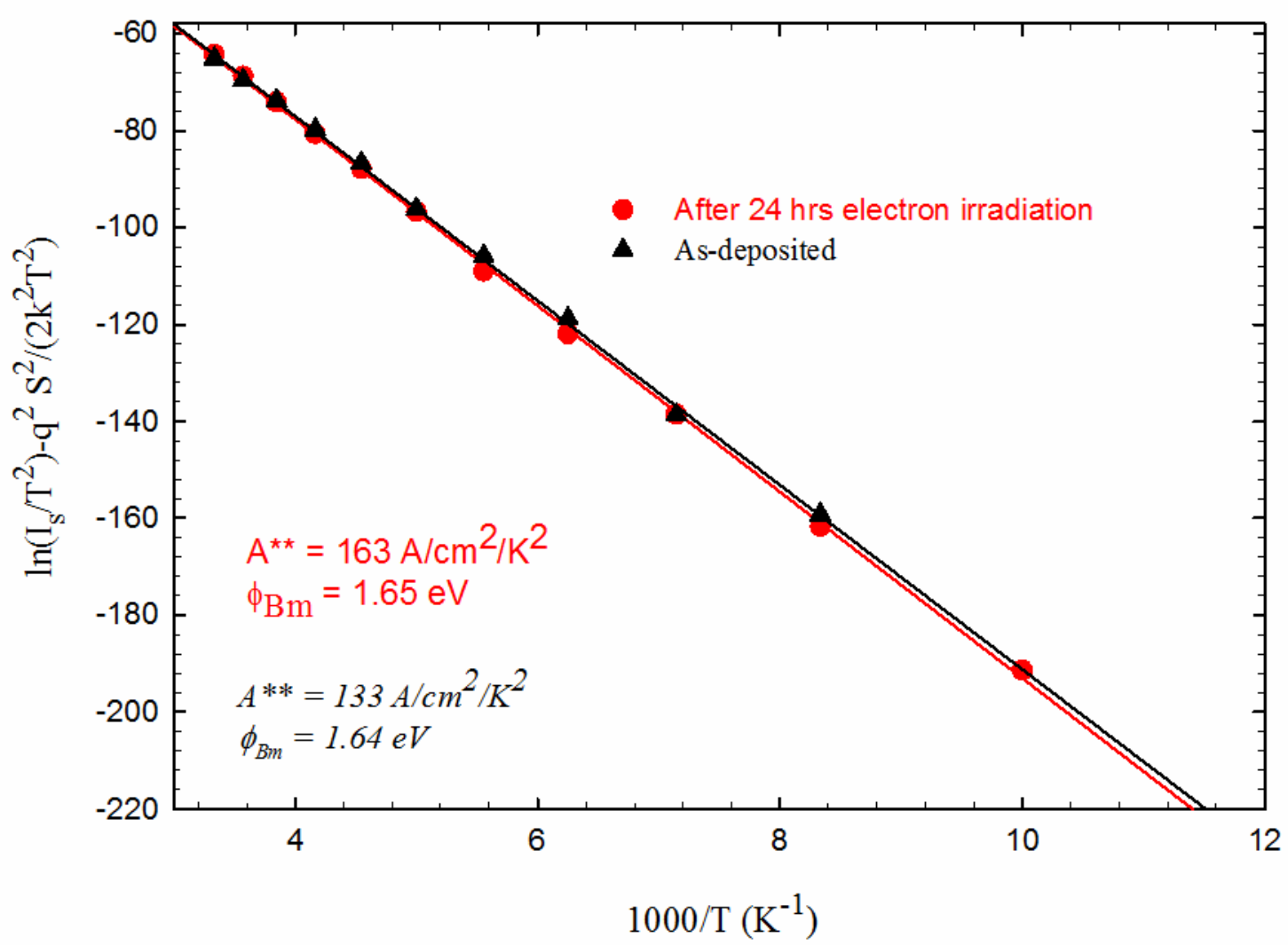

Fig. 7. The modified Richardson plot for Ni/4H-SiC Schottky diode before and after electron irradiation at temperature range 40-300 K.

Fig. 7 shows the plot of $\ln \left(I_{s} / T^{2}\right)-\left(q^{2} \sigma^{2} / 2 k^{2} T^{2}\right)$ as function of $1000 / T$. The mean $\bar{\phi}_{B O}$ was determined directly from the slope of the plot to be $1.64 \pm 0.01 \mathrm{eV}$ and $1.65 \pm 0.01 \mathrm{eV}$ for as-deposited and irradiated devices, respectively. The zero mean barrier height obtained was much closer to those obtained from the plot $\phi_{\mathrm{ap}} \mathrm{vs} 1 / 2 \mathrm{kT}$ in Fig. 6. The modified Richardson constants, $A * *$ before and after HEE irradiation were determined from the intercept of the straight line to be 133 and $163 \mathrm{Acm}^{-2} \mathrm{~K}^{-2}$, respectively. The values were in good agreement with the theoretical value of $146 \mathrm{Acm}^{-2} \mathrm{~K}^{-2}[49,60]$, though higher due to spatially inhomogeneous SBHs [20]. The modified Richardson constant obtained was in line with what has been observed during the alpha-particle irradiation [31]. The values of $\bar{\phi}_{B O}$ and $A * *$ for as-deposited and irradiated 
devices showed the extent at which $\mathrm{Ni} / 4 \mathrm{H}-\mathrm{SiC}$ SBDs could be affected by HEE irradiation at the aforementioned fluence. From these results, we concluded that the HEE irradiation did not influence the mean barrier height, but did influence modified Richardson constant. The same conclusion has been drawn for alphaparticle irradiated $4 \mathrm{H}-\mathrm{SiC}$ SBDs [31].

\subsection{Deep Level Transient Spectroscopy (DLTS)}

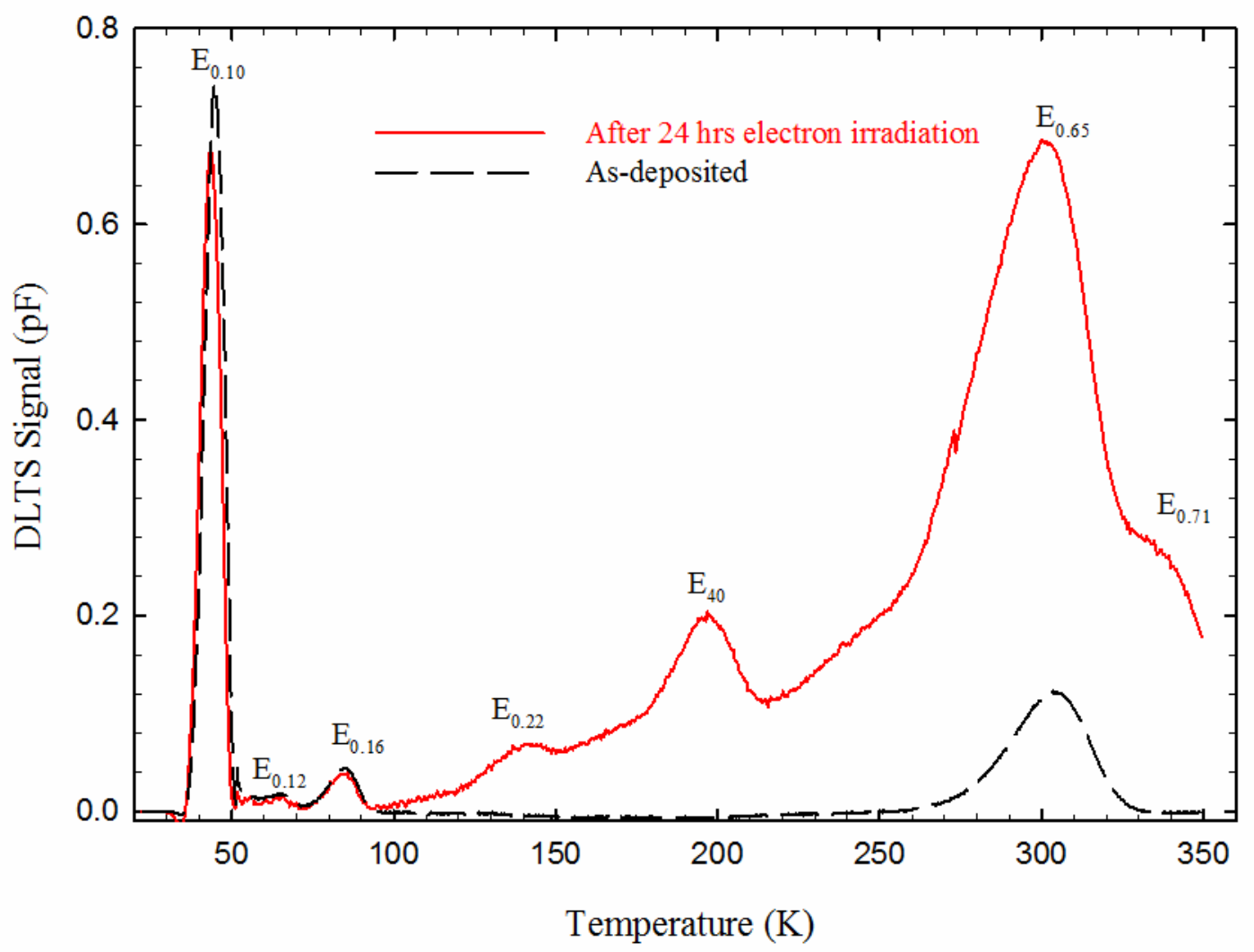

Fig. 8. DLTS spectra for the Ni/4H-SiC before and after electron irradiation. The temperature range $52-350 \mathrm{~K}$ scaled up by factor 10 .

Fig. 8 shows the DLTS spectra for the samples before and after HEE irradiation. Fig. 9 shows the Arrhenius plots. The measurements were obtained at temperatures range 22-350 K, at a quiescent reverse bias of $-5.0 \mathrm{~V}$, filling pulse height of $1.0 \mathrm{~V}$, filling pulse width of $2.0 \mathrm{~ms}$ and a rate window of $20 \mathrm{~s}^{-1}$. The sample before irradiation revealed four defects with levels labelled as $\mathrm{E}_{0.10}, \mathrm{E}_{0.12}, \mathrm{E}_{0.16}$ and $\mathrm{E}_{0.65}$ and their corresponding apparent capture cross sections were $3 \times 10^{-11} \mathrm{~cm}^{2}, 1 \times 10^{-15} \mathrm{~cm}^{2}, 1 \times 10^{-15} \mathrm{~cm}^{2}$ and $4 \times 10^{-15} \mathrm{~cm}^{2}$, respectively. The sample after irradiation revealed seven defects with energy levels labelled as $\mathrm{E}_{0.10}, \mathrm{E}_{0.12}, \mathrm{E}_{0.16}$, $\mathrm{E}_{0.22}, \mathrm{E}_{0.40}, \mathrm{E}_{0.65}$ and $\mathrm{E}_{0.71}$, and their corresponding apparent capture cross sections were $1 \times 10^{-16} \mathrm{~cm}^{2}$, $4 \times 10^{-12} \mathrm{~cm}^{2}, 1 \times 10^{-15} \mathrm{~cm}^{2}, 2 \times 10^{-17} \mathrm{~cm}^{2}, 3 \times 10^{-15} \mathrm{~cm}^{2}, 3 \times 10^{-15} \mathrm{~cm}^{2}$ and $3 \times 10^{-15} \mathrm{~cm}^{2}$. Some of these defects were confirmed from the literature [61]. Three new defects $\left(\mathrm{E}_{0.22}, \mathrm{E}_{0.40}\right.$ and $\left.\mathrm{E}_{0.71}\right)$ were introduced after the sample was irradiated by HEE. The formation of new defects caused changes in the $I-V$ and $C-V$ characteristics and the parameters of the Schottky barrier diodes. 


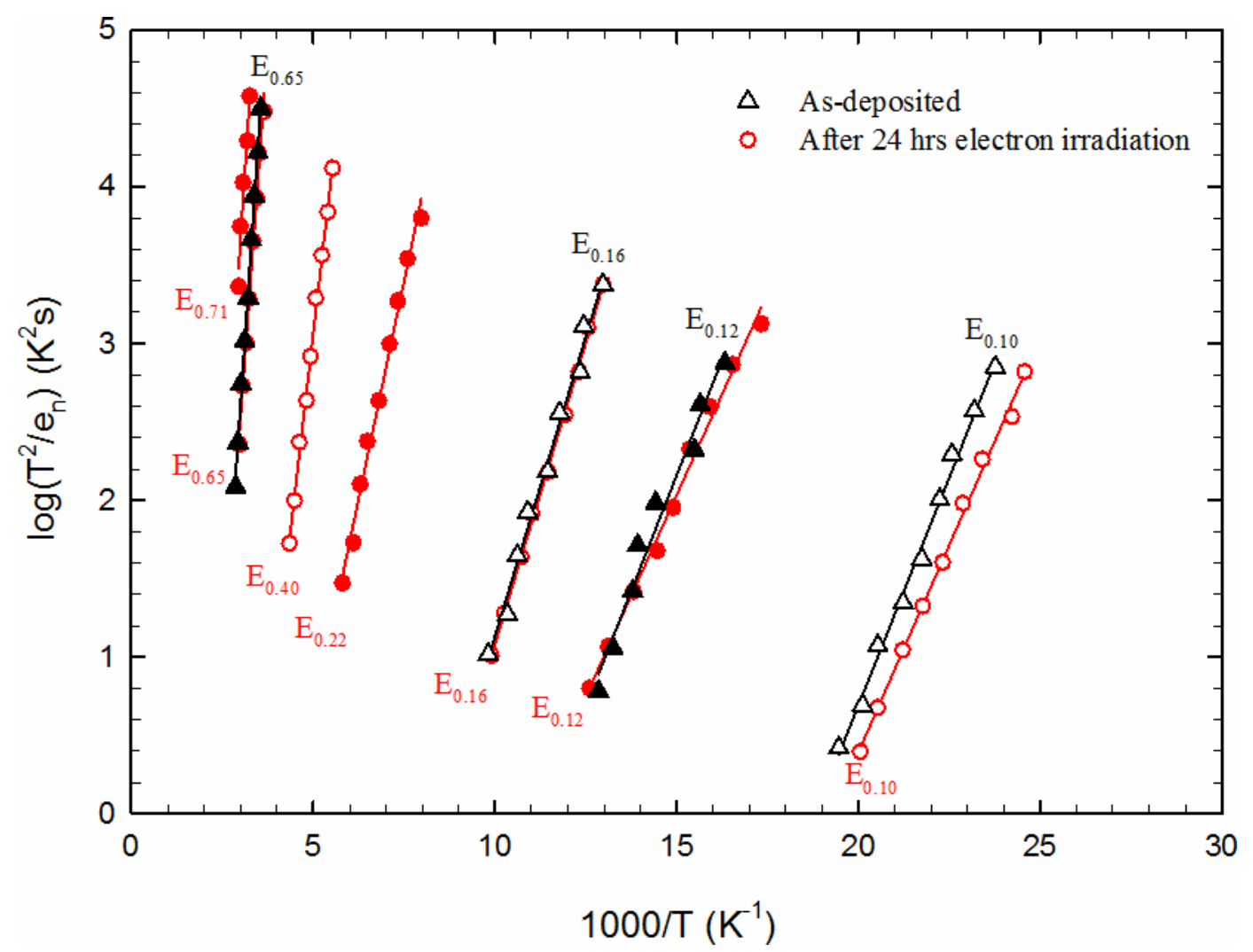

Fig. 9. The Arrhenius plots for the DLTS of as-deposited and after irradiation Ni/4H-SiC.

\section{Conclusions}

The Ni/4H-SiC Schottky contacts were successfully fabricated by resistive evaporation. The $I-V$ and $C-V$ measurements at $300 \mathrm{~K}$ before and after fluence of $6 \times 10^{14}$ electrons-cm ${ }^{-2}$ irradiation revealed good Schottky contacts which alone did not provide satisfactory results. From the forward $I-V$ measurements, $n, \mathrm{SBH}, R_{s}$ increased with irradiation but $I_{s}$ decreased with irradiation measured at $300 \mathrm{~K}$. The reverse currents were significantly constant within the range of our system. $C-V$ measurements revealed a decrease in free carrier concentration. The effects of high energy electron irradiations on Ni/4H-SiC SBD was also investigated using $I$ $V, C$ - $V$ and DLTS, measured in a wide temperature range 40-300 K. For the temperature range 80-300 K, thermionic emission was the dominant transport mechanism. Generation-recombination proved to be dominant at temperatures below $80 \mathrm{~K}$. The ideality factor and SBH of the devices had strong reciprocal temperature dependence at lower temperature. The modified Richardson constants before and after HEE irradiation were 133 and $163 \mathrm{Acm}^{-2} \mathrm{~K}^{-2}$, respectively, by using Gaussian distribution method. The values of $A^{* *}$ were in good agreement with the theoretical value. We concluded that HEE irradiation of fluence $6 \times 10^{14}$ electrons-cm $^{-2}$ did not influence the mean barrier height, but did influence modified Richardson constant. The removal rate of approximately $1.67 \mathrm{~cm}^{-1}$ was calculated which corroborate the use of $\mathrm{SiC}$ in radiation harsh environments.

\section{Acknowledgements}

This work is based on the research supported in part by the National Research Foundation (NRF) of South African (Grant specific unique reference number (UID) 78838). The Grant holder acknowledges that opinions, findings and conclusions or recommendations expressed in this publication generated by the NRF supported are that of authors and that NRF accepts no liability whatsoever in this regard. 


\section{References}

[1] R.L. Van Tuyl, C.A. Liechti, Solid-State Circuits, IEEE Journal of, 9 (1974) 269-276.

[2] A. Elasser, M.H. Kheraluwala, M. Ghezzo, R.L. Steigerwald, N.A. Evers, J. Kretchmer, T.P. Chow, Industry Applications, IEEE Transactions on, 39 (2003) 915-921.

[3] S. Takayuki, U. Tsuneo, S. Seizo, M. Yoshihiko, Japanese Journal of Applied Physics, 19 (1980) 459.

[4] A.F. Özdemir, A. Turut, A. Kökçe, Semiconductor Science and Technology, 21 (2006) 298.

[5] E. Rhoderick, R. Williams, Oxford Science, Oxford, 1988.

[6] V. Janardhanam, A. Ashok Kumar, V. Rajagopal Reddy, P. Narasimha Reddy, Journal of Alloys and Compounds, 485 (2009) 467-472.

[7] S. Zeyrek, M.M. Bulbul, S. Altindal, M.C. Baykul, H. Yuzer, Brazilian Journal of Physics, 38 (2008) 591597.

[8] İ. Dökme, Ş. Altindal, M.M. Bülbül, Applied Surface Science, 252 (2006) 7749-7754.

[9] Ş. Karataş, Ş. Altindal, M. Çakar, Physica B: Condensed Matter, 357 (2005) 386-397.

[10] S. Zhu, R.L. Van Meirhaeghe, C. Detavernier, F. Cardon, G.P. Ru, X.P. Qu, B.Z. Li, Solid-State Electronics, 44 (2000) 663-671.

[11] A. Gümüş, A. Türüt, N. Yalçin, Journal of Applied Physics, 91 (2002) 245-250.

[12] J.H. Werner, H.H. Güttler, Journal of Applied Physics, 69 (1991) 1522-1533.

[13] C. Subhash, Semiconductor Science and Technology, 19 (2004) 82.

[14] Y.P. Song, R.L. Van Meirhaeghe, W.H. Laflère, F. Cardon, Solid State Electronics, 29 (1986) 633-638.

[15] P.G. McCafferty, A. Sellai, P. Dawson, H. Elabd, Solid-State Electronics, 39 (1996) 583-592.

[16] L.M. Tolbert, B. Ozpineci, S.K. Islam, M.S. Chinthavali, Power and Energy Systems, Proceedings, 1 (2003) 317-321.

[17] V. Kazukauskas, J.-V. Vaitkus, Opto-Electronic Review, 12 (2004) 377-382.

[18] J. Grant, W. Cunningham, A. Blue, V. O’Shea, J. Vaitkus, E. Gaubas, M. Rahman, Nuclear Instruments and Methods in Physics Research Section A: Accelerators, Spectrometers, Detectors and Associated Equipment, 546 (2005) 213-217.

[19] M.C. Driver, R.H. Hopkins, C.D. Brandt, D.L. Barrett, A.A. Burk, R.C. Clarke, G.W. Eldridge, H.M. Hobgood, J.P. McHugh, P.G. McMullin, R.R. Siergiej, S. Sriram, Gallium Arsenide Integrated Circuit (GaAs IC) Symposium, 1993. Technical Digest 1993., 15th Annual, 1993, pp. 19-21.

[20] V. Kumar, A.S. Maan, J. Akhtar, Journal of Vacuum Science \&amp; Technology B, 32 (2014) 041203.

[21] A. Akbay, H. Korkut, K. Ejderha, T. Korkut, A. Türüt, Journal of Radioanalytical and Nuclear Chemistry, 289 (2011) 145-148.

[22] K. Çınar, C. Coşkun, Ş. Aydoğan, H. Asıl, E. Gür, Nuclear Instruments and Methods in Physics Research Section B: Beam Interactions with Materials and Atoms, 268 (2010) 616-621.

[23] K. Çınar, C. Coşkun, E. Gür, Ş. Aydoğan, Nuclear Instruments and Methods in Physics Research Section B: Beam Interactions with Materials and Atoms, 267 (2009) 87-90.

[24] J. Benkovska, L. Stuchlikova, D. Buc, L. Čaplovic, physica status solidi (a), 209 (2012) 1384-1389.

[25] T. Marinova, A. Kakanakova-Georgieva, V. Krastev, R. Kakanakov, M. Neshev, L. Kassamakova, O. Noblanc, C. Arnodo, S. Cassette, C. Brylinski, B. Pecz, G. Radnoczi, G. Vincze, Materials Science and Engineering: B, 46 (1997) 223-226.

[26] F.D. Auret, S.A. Goodman, G. Myburg, W.O. Barnard, D.T.L. Jones, Journal of Applied Physics, 74 (1993) 4339-4342.

[27] S. Ashok, J.M. Borrego, R.J. Gutmann, Journal of Applied Physics, 51 (1980) 1076-1084.

[28] F. Roccaforte, S. Libertino, F. Giannazzo, C. Bongiorno, F. La Via, V. Raineri, Journal of Applied Physics, 97 (2005) -.

[29] C. Raynaud, K. Isoird, M. Lazar, C.M. Johnson, N. Wright, Journal of Applied Physics, 91 (2002) 9841 9847.

[30] F. Auret, S. Goodman, M. Hayes, M. Legodi, H. Van Laarhoven, D.C. Look, Applied Physics Letters, 79 (2001) 3074-3076.

[31] E. Omotoso, W.E. Meyer, F.D. Auret, A.P. Paradzah, M. Diale, S.M.M. Coelho, P.J. Janse Van Rensberg, Nuclear Instruments and Methods in Physics Research Section B: Beam Interactions with Materials and Atoms, submitted for publication.

[32] S.M. Sze, K.K. Ng, Physics of semiconductor devices, John Wiley \& Sons, 2006.

[33] M.E. Aydın, N. Yıldırım, A. Türüt, Journal of Applied Physics, 102 (2007) 043701.

[34] Z. Ouennoughi, S. Toumi, R. Weiss, Physica B: Condensed Matter, 456 (2015) 176-181.

[35] M. Gülnahar, Superlattices and Microstructures, 76 (2014) 394-412.

[36] S. Alialy, Ş. Altındal, E.E. Tanrıkulu, D.E. Yıldız, Journal of Applied Physics, 116 (2014) 083709.

[37] S. Shankar Naik, V. Rajagopal Reddy, Superlattices and Microstructures, 48 (2010) 330-342.

[38] Z. Lin, Z. Yi-Men, Z. Yu-Ming, H. Chao, M. Yong-Ji, Chinese Physics B, 18 (2009) 1931.

[39] E. Hökelek, G.Y. Robinson, Applied Physics Letters, 40 (1982) 426-428. 
[40] C.R. Crowell, V.L. Rideout, Solid-State Electronics, 12 (1969) 89-105.

[41] M. Soylu, B. Abay, Microelectronic Engineering, 86 (2009) 88-95.

[42] M. Soylu, F. Yakuphanoglu, Journal of Alloys and Compounds, 506 (2010) 418-422.

[43] C. Coskun, N. Gedik, E. Balc1, Semiconductor science and technology, 21 (2006) 1656.

[44] C.R. Crowell, Solid-State Electronics, 20 (1977) 171-175.

[45] R.R. Ciechonski, Device Characteristics of Sublimation Grown 4H-SiC Layers, Univ., 2005.

[46] L. Huang, F. Qin, S. Li, D. Wang, Applied Physics Letters, 103 (2013) 033520.

[47] S. Toumi, A. Ferhat-Hamida, L. Boussouar, A. Sellai, Z. Ouennoughi, H. Ryssel, Microelectronic Engineering, 86 (2009) 303-309.

[48] D.K. Schroder, A John Willey \& Sons, inc., , 3rd Edition (2006).

[49] A. Itoh, T. Kimoto, H. Matsunami, Electron Device Letters, IEEE, 16 (1995) 280-282.

[50] F. Roccaforte, F. La Via, A. Baeri, V. Raineri, L. Calcagno, F. Mangano, Journal of Applied Physics, 96 (2004) 4313-4318.

[51] J.H. Werner, H.H. Güttler, Journal of Applied Physics, 73 (1993) 1315-1319.

[52] M.K. Hudait, P. Venkateswarlu, S.B. Krupanidhi, Solid-State Electronics, 45 (2001) 133-141.

[53] S. Zhu, R.L. Van Meirhaeghe, C. Detavernier, G.P. Ru, B.Z. Li, F. Cardon, Solid State Communications, 112 (1999) 611-615.

[54] S. Zeyrek, Ş. Altındal, H. Yüzer, M.M. Bülbül, Applied Surface Science, 252 (2006) 2999-3010.

[55] P.M. Gammon, A. Pérez-Tomás, V.A. Shah, O. Vavasour, E. Donchev, J.S. Pang, M. Myronov, C.A. Fisher, M.R. Jennings, D.R. Leadley, P.A. Mawby, Journal of Applied Physics, 114 (2013) 223704.

[56] Y.P. Song, R.L. Van Meirhaeghe, W.H. Laflère, F. Cardon, Solid-State Electronics, 29 (1986) 633-638.

[57] S. Chand, S. Bala, Applied Surface Science, 252 (2005) 358-363.

[58] E. Özavcı, S. Demirezen, U. Aydemir, Ş. Altındal, Sensors and Actuators A: Physical, 194 (2013) 259-268.

[59] H. Tecimer, S. Aksu, H. Uslu, Y. Atasoy, E. Bacaksız, Ş. Altındal, Sensors and Actuators A: Physical, 185 (2012) 73-81.

[60] F. Roccaforte, C. Bongiorno, F. La Via, V. Raineri, Applied Physics Letters, 85 (2004) 6152.

[61] V.V. Kozlovskiǔ, V.V. Emtsev, K.V. Emtsev, N.B. Strokan, A.M. Ivanov, V.N. Lomasov, G.A. Oganesyan, A.A. Lebedev, Semiconductors, 42 (2008) 242-247. 